\title{
Humeral shaft fracture: a randomized controlled trial of nonoperative versus operative management (plate fixation)
}

This article was published in the following Dove Press journal: Orthopedic Research and Reviews

\author{
Seyed Mahdi \\ Hosseini Khameneh \\ Mohammadreza Abbasian' \\ Hashem Abrishamkarzadeh ${ }^{1,2}$ \\ Shahab Bagheri (iD ${ }^{3}$ \\ Fahimeh Abdollahimajd (iD) ${ }^{4}$ \\ Farshad Safdari (D) $^{5}$ \\ Shahram Rahimi-Dehgolan (iD ${ }^{6}$ \\ 'Orthopedic Surgery Department, Bone, \\ Joint, and Related Tissues Research Center, \\ Akhtar Educational Hospital, Shahid \\ Beheshti University of Medical Sciences, \\ Tehran, Iran; ${ }^{2}$ Orthopedic Surgery \\ Department, AJA University of Medical \\ Sciences, Tehran, Iran; ${ }^{3}$ Physical Medicine \\ and Rehabilitation Department, Shahid \\ Beheshti University of Medical Sciences, \\ Tehran, Iran; ${ }^{4}$ Skin Research Center, Shahid \\ Beheshti University of Medical Sciences, \\ Tehran, Iran; ${ }^{5}$ Orthotics and Prosthetics \\ Department, Bone, Joint, and Related \\ Tissues Research Center, Shahid Beheshti \\ University of Medical Sciences, Tehran, Iran; \\ ${ }^{6}$ Physical Medicine and Rehabilitation \\ Department, School of Medicine, Tehran \\ University of Medical Sciences (TUMS), \\ Tehran, Iran
}

Correspondence: Hashem Abrishamkarzadeh

Orthopedic Surgery Department, Bone, Joint, and Related Tissues Research Center, Akhtar Educational Hospital, Shahid Beheshti University of Medical Sciences, Sharif Manesh Street, Poule Roomi Avenue, Shariati Street, Tehran 19647|4953, Iran Tel/fax +98 2/2 2074090

Email Hashem.abrishamkar@gmail.com

Shahram Rahimi-Dehgolan

Physical Medicine and Rehabilitation Department, IKHC Center, Keshavarz Boulevard, Tehran I4|9733|4I, Iran $\mathrm{Tel} / \mathrm{fax}+982161190$

Email shahram.rahimi.dehgolan@gmail.com
Purpose: This randomized controlled trial was conducted to investigate the outcomes of humeral shaft-fracture management with the functional Sarmiento brace (nonoperative) versus open reduction internal fixation (ORIF).

Methods: Sixty humeral shaft-fracture patients with a minimum age of 18 years were randomly assigned into two groups: operative treatment with open reduction-internal fixation (ORIF) or functional brace (Sarmiento). A similar postoperative rehabilitation program was applied for all subjects for the next 12 months. The outcomes of each method were measured in terms of nonunion rate, union time, "quick" Disabilities of Arm, Shoulder, and Hand (DASH) questionnaire scores, and rate of complications, such as malunion, infection, and radial nerve injury.

Results: The two groups had similar baseline characteristics, including age, sex, smoking status, and type and mechanism of fracture. The mean union time was about 4.8 weeks shorter in the ORIF group (13.9 weeks in operative group versus 18.7 weeks in nonoperative group), indicating a definite significant superiority $(p=0.001)$ of ORIF management to functional Sarmiento bracing. However, a comparison of quick DASH scores revealed a borderline-significant difference between the groups ( $p=0.065$ ). Additionally, we found that treatment of humeral shaft fractures using functional bracing was associated with slightly higher risk of nonunion; however this was not significant $(p=0.492)$.

Conclusion: According to the present findings, there is remarkable superiority of ORIF over functional Sarmiento bracing in the management of patients with humeral shaft fracture.

Keywords: diaphyseal fracture, functional brace, open reduction internal fixation, malunion, nonunion

\section{Introduction}

Humeral shaft fractures (HSFs) are one of the most common injuries in trauma centers. ${ }^{1}$ These fractures account for approximately $1 \%-5 \%$ of all fractures in adults and nearly $20 \%$ of all humeral fractures..$^{2-4}$ Several treatment strategies have been introduced for management of HSF, including casting, functional bracing, open reduction-internal fixation (ORIF), minimally invasive plate osteosynthesis, intramedullary nailing, and external fixation. Each of these modalities has its own advantages and disadvantages. ${ }^{5-9}$ For instance, nonoperative treatment, such as functional bracing, has been considered an efficient method for isolated HSFs. ${ }^{10-15}$ However, it might be associated with some complications, such as nonunion, angulation, malunion, shoulder impingement, skin abrasion, limited range of motion (ROM), and long-lasting treatment. $^{7,14-18}$ 
Surgical treatment is indispensable in certain circumstances, including types II and III Gustilo open fractures, multiple trauma, high-energy trauma, neurovascular injuries, floating elbow, bilateral SFs, segmental fractures, oblique fractures in the proximal third, SFs of the distal third, fractures with axial distraction, unsatisfactory reductions, pathological fractures, and delayed union, nonunion, or malunion after conservative management. It might also be indicated for obese patients or those with a psychiatric disorder, such as dementia, psychosis, or bipolar disorder. ${ }^{17}$ Although the optimal surgical treatment of HSF remains controversial, such fixation methods as compression plating and intramedullary nailing are preferred over others and are commonly used. ${ }^{9,19}$ Furthermore, intramedullary nailing has been recommended as the treatment of choice; however, there may be some disadvantages and complications. ${ }^{9,19}$

In spite of several investigations, few studies have compared operative versus nonoperative treatments of HSFs. ${ }^{8,11,14,20}$ In this regard, a systematic review in 2015 showed that no randomized clinical trials (RCTs) with good quality evidence had been conducted to compare the outcomes of surgical and nonsurgical interventions. ${ }^{11}$ Moreover, another recent systematic review demonstrated that there was not enough evidence to determine whether operative or nonoperative treatment is superior in HSFs. ${ }^{8}$ As such, further investigations should be conducted to shed light on the efficacy of operative versus nonoperative treatments in HSFs. To the best of our knowledge, at present few published RCTs have compared the benefits of minimally invasive surgery versus functional bracing for HSF patients. ${ }^{21}$ Therefore, the present RCT aimed to compare clinical, functional, and radiological outcomes and the rate of complications among HSF patients treated with ORIF versus those receiving a functional Sarmiento brace.

\section{Methods}

\section{Participants}

This RCT was performed between January and December 2016 on 60 patients with isolated HSFs. HSF was defined as a fracture found on plain radiography between the proximal and distal metaphyses without extension to proximal and distal articular surfaces, ie, AO classes of $12 \mathrm{~A}_{1,2,3}$ (www.aofoundation.org). The study methodology was evaluated based on the Consolidated Standards of Reporting Trials (CONSORT) checklist, and was performed in accordance with Declaration of Helsinki principles. All the ethical issues of dealing with human participants were considered carefully and approved by the ethical committee of Shahid Beheshti University of Medical Sciences. Patients under the age of 18 years or who had diabetes mellitus, rheumatoid arthritis, pathological or open fractures, bilateral fractures, concomitant shoulder or elbow injuries, multiple trauma, and concurrent neurovascular injuries were excluded from the study. Patients with fractures $>3$ weeks were also excluded from the study. A signed informed consent letter was taken from each of the eligible patients at the beginning of the study. Eventually, a random-number generator was used to divide patients into two equal groups: operative treatment (ORIF) versus using a functional brace called Sarmiento.

\section{Nonoperative management (Sarmiento)}

After closed reduction, the arm was immobilized initially with a U-splint (from the axilla to the elbow). Approximately 2 weeks later, this was replaced by a Sarmiento functional brace that allowed patients to move their elbow and shoulder based on a regular rehabilitation protocol. This brace remained for 6 weeks or until consolidation of the fracture.

\section{Operative management (ORIF)}

The operation was performed under general anesthesia in lateral decubitus while the elbow was in a semiflexed position. A longitudinal anterolateral incision was made from the coracoid tip of the scapula toward the lateral border of the biceps brachialis muscle $5 \mathrm{~cm}$ before the cubital fossa. After open reduction, the fracture site was fixated using a narrow lapping/dynamic compression plate of $3.5 \mathrm{~mm}$ thickness with eight to ten holes on both sides. The fixation was initially made using three cortical screws, and then locking screws were applied. After the final intraoperative radiological evaluation, a drain was placed. The wound was sutured and dressing performed. Also, the limb was postoperatively placed in an arm sling for at least 2-3 days. Gentle ROM exercises for elbow, wrist, and finger joints were commenced within 3 days of surgery, and an earlyrehabilitation program continued for 6 weeks, along with strict weight-lifting instructions $(<0.5 \mathrm{~kg})$. After 6 weeks, shoulder ROM exercises, including pendulum protocol and then active ROM, such as internal/external shoulder rotation based on the patient's tolerance, were started. Also, the late postoperative rehabilitation program was similar for all subjects and continued for 1 year. 


\section{Outcome assessment}

Demographics of patients - sex, age, smoking status, type of fracture (simple, segmental, wedge), and mechanism of injury - were recorded before the study began. Patients were examined at the beginning of the study and weeks 2 and 4 after the treatment. They were revisited monthly until complete union was observed. Union was defined as the absence of pain or tenderness at the fracture site and the presence of three bridging cortices on two orthogonal views on monthly radiography. Along with radiographic assessments, clinical parameters were also evaluated. In addition, another X-ray image was taken for each patient who had undergone plate fixation. The final visit took place 1 year postoperatively. The time required for radiological occurrence of union was recorded. Nonunion was considered as the fracture failing to unite after 6 months. The presence of malunion (angulation $>20^{\circ}$ in sagittal or coronal planes) was evaluated and the "quick" Disabilities of Arm, Shoulder, and Hand (DASH) questionnaire used for all patients to investigate functional outcomes.

\section{Statistical analysis}

Final data before and after the treatment were imported and analyzed in SPSS version 22. Normality of data was evaluated using the Shapiro-Wilk test. Qualitative variables are expressed as frequency and percentage. Fisher's exact test or $\chi^{2}$ were utilized to compare the rate of union, malunion, and other complications. Mean values of union time and raw mean differences in quick DASH scores were compared utilizing independent-sample $t$-tests. Retrospective power estimation was done for borderlinesignificant $p$-values. Statistical significance was set at $p<0.05$.

\section{Results}

A total of 60 participants were involved in the present investigation. Demographic data of the two groups are shown in Table 1. Baseline characteristics of the two groups in terms of age, sex, and smoking status were almost similar. Moreover, both groups had the same mechanism of injury $(p=0.317)$ and type of fracture ( $p=0.433$ ). About half the injuries were found to be the result of vehicle accidents. The majority of fractures belonged to the simple type ( $60 \%$ in operative group and $70 \%$ in nonoperative group).

Time to radiological union, rate of nonunion, and quick DASH scores in the two groups are summarized in
Table 2. Median union time was 14 weeks (mean 13.9 weeks) in the operative group and 18 weeks (mean 18.7 weeks) for the nonoperative group, indicating that ORIF treatment was associated with complete union about 4 weeks earlier than the Sarmiento group. This difference was statistically significant $(p=0.001)$. On the other hand, DASH-score comparison revealed a borderline-significant difference $(p=0.065)$. In the functional brace group, nonunion occurred in two patients $(p=0.492)$ who eventually underwent surgical management.

As mentioned before, those patients with initial radial nerve injury were excluded from the study. However, among the 30 eligible patients assigned to the operative group, $18(60 \%)$ were identified with neuroapraxia that was transient and fully resolved within 3-6 months of conservative management. Fortunately, there were no cases of malunion, infection, or severe radial nerve injury in the present study.

\section{Discussion}

Based on the findings, patients in the ORIF group had a mean union time of 4.8 weeks less than those who received the functional Sarmiento brace (13.9 weeks in operative group versus 18.7 weeks in nonoperative group). As we mentioned, this comparison showed a remarkable superiority of operative management over Sarmiento bracing. Similarly, DASH-score improvement was higher in the operative group than the nonoperative group. However, the latter difference was not statistically significant, revealing a borderline value. A retrospective power calculation demonstrated that this might have occurred due to the small sample: a larger population of 70 patients would be required to detect a definite significant difference. Patients who received the functional bracing experienced a higher risk $(6.6 \%)$ of nonunion than patients treated by ORIF. However, the differences between the groups were not significant $(p=0.492)$. Although results in terms of nonunion rate and DASHscore improvement were not statistically significant, overall a remarkable advantage was observed favoring ORIF treatment for HSFs over the functional Sarmiento bracing. In contrast to our results, conservative management of HSFs has been reported with favorable outcomes in most patients. Some complications, such as iatrogenic radial nerve injury or nonunion, are unavoidable in certain cases. Altogether, there is still considerable debate regarding the application of surgical or nonsurgical methods as the treatment of choice. ${ }^{8,22}$ 
Table I Baseline demographics of the two groups

\begin{tabular}{|c|c|c|c|c|}
\hline & & $\begin{array}{l}\text { Operative } \\
(n=30)\end{array}$ & $\begin{array}{l}\text { Nonoperative } \\
(n=30)\end{array}$ & $p$-value \\
\hline \multicolumn{2}{|c|}{ Age, (years), mean \pm SD (range) } & $\begin{array}{l}37.7 \pm \mid 5.4 \\
(|8-7|)\end{array}$ & $\begin{array}{l}48.5 \pm 19.4 \\
(19-77)\end{array}$ & 0.202 \\
\hline Sex, n (\%) & $\begin{array}{l}\text { Male } \\
\text { Female }\end{array}$ & $\begin{array}{l}23(77 \%) \\
7(23 \%)\end{array}$ & $\begin{array}{l}26(87 \%) \\
4(13 \%)\end{array}$ & 0.317 \\
\hline Type of fracture, $n$ (\%) & $\begin{array}{l}\text { Simple } \\
\text { Segmental } \\
\text { Wedge }\end{array}$ & $\begin{array}{l}18(60 \%) \\
8(27 \%) \\
4(13 \%)\end{array}$ & $\begin{array}{l}21(70 \%) \\
4(13 \%) \\
5(17 \%)\end{array}$ & 0.433 \\
\hline Mechanism of injury, n (\%) & $\begin{array}{l}\text { Vehicle accident } \\
\text { Sport injuries } \\
\text { Falling down }\end{array}$ & $\begin{array}{l}12(40 \%) \\
10(33 \%) \\
8(27 \%)\end{array}$ & $\begin{array}{l}16(53 \%) \\
5(17 \%) \\
9(30 \%)\end{array}$ & 0.317 \\
\hline Smoking status, n (\%) & $\begin{array}{l}\text { Nonsmoker } \\
\text { Passive smoker } \\
\text { Smoker }\end{array}$ & $\begin{array}{l}6(20 \%) \\
15(50 \%) \\
9(30 \%)\end{array}$ & $\begin{array}{l}8(27 \%) \\
9(30 \%) \\
13(43 \%)\end{array}$ & 0.285 \\
\hline
\end{tabular}

Table 2 Clinical, functional, and radiological outcomes

\begin{tabular}{|c|c|c|c|}
\hline & $\begin{array}{l}\text { Operative } \\
(n=30)\end{array}$ & $\begin{array}{l}\text { Nonoperative } \\
(n=30)\end{array}$ & $p$-value \\
\hline $\begin{array}{l}\text { Change in DASH } \\
\text { score, mean } \pm \text { SD } \\
\text { (range) }\end{array}$ & $\begin{array}{l}29.1 \pm 3.7 \\
(15.9-40.5)\end{array}$ & $\begin{array}{l}26.7 \pm 5.9 \\
(20.5-42.7)\end{array}$ & 0.065 \\
\hline $\begin{array}{l}\text { Mean union time } \\
\text { (weeks), mean } \pm \text { SD } \\
\text { (range) }\end{array}$ & $\begin{array}{l}|3.9 \pm 2 .| \\
(12-20)\end{array}$ & $\begin{array}{l}18.7 \pm 3.0 \\
(12-24)\end{array}$ & 0.001 \\
\hline Nonunion, n (\%) & 0 & $\begin{array}{l}2 \\
(6.6 \%)\end{array}$ & 0.492 \\
\hline
\end{tabular}

Abbreviation: DASH, Disabilities of Arm, Shoulder, and Hand.

Since the humerus is not a weight-bearing bone, unlike the other long bones, compressive forces have no important role in its healing process. Additionally, because the glenohumeral joint has extensive ROM without producing torsional stress, there is no need for rigid immobilization in HSFs. Instead, gravity-assisted realignment of segments will occur. ${ }^{23}$ This concept propelled Sarmiento et al to describe functional bracing in which the fracture site is immobilized utilizing a compressive effect of the brace on the surrounding soft tissue, while realignment of the fractured fragments is achieved via the effect of gravity. ${ }^{24}$ Furthermore, early mobilization of the shoulder and elbow is preserved, with functional bracing enhancing osteogenesis and the healing process. ${ }^{23,25}$

Oztürk et al evaluated the outcomes of functional bracing in 38 patients with humeral diaphyseal fractures.
Complete union was obtained in all subjects, and angulation did not exceeded $20^{\circ}$ in the sagittal plane or $10^{\circ}$ in the coronal plane in any cases. They assumed that among nonoperative methods, functional bracing was the best to treat humeral diaphyseal fractures. ${ }^{26}$ Papasoulis et al showed an average healing time of 10.7 weeks, and the union rate was $94.5 \%$ for HSF management by functional bracing. Full shoulder and elbow ROM was obtained in about $80 \%$ of the subjects. Angulation seldom exceeded $10^{\circ} .{ }^{15}$ In another study conducted by Pehlivan et al, the average union time was 12 weeks in 21 distal-third HSFs, and no case of nonunion or radial nerve palsy occurred. ${ }^{25}$ Similarly, in our study no case of malunion, infection, or severe radial nerve injury was found and the results were in line with the aforementioned studies.

With the satisfying outcomes mentioned, functional bracing might be considered as the gold standard method for the HSF in a majority of cases. ${ }^{10-15}$ However, some authors are concerned about unsatisfactory results and several complications, such as shoulder impingement, angulation, and skin abrasion in nonoperative treatment among certain patient groups. ${ }^{12,27-29}$ Wallny et al demonstrated that $14 \%$ of patients treated with functional bracing had limited ROM and 12.6\% had malunion $>10^{\circ} .{ }^{16}$ Also, Koch et al found that $13.4 \%$ of patients treated with Sarmiento bracing failed to heal and eventually underwent operative management. ${ }^{12}$ Pehlivan et al demonstrated that varus angulation (average $7.8^{\circ}$ ) and shortening (average $10 \mathrm{~mm}$ ) were found in $38 \%$ and $19 \%$ of patients treated with functional bracing, respectively. 
Additionally, there was minimal limitation in ROM observed in shoulder abduction and lateral rotation. ${ }^{25}$ However, it seems that this amount of angulation or shortening had no clinical or functional importance. In fact, these findings confirm the concerns about complications after nonoperative HSF treatment. Some recent studies have questioned nonoperative treatment for all HSFs and suggested that surgery is preferred in cases with neurovascular, medullar, or brachial plexus injuries, open fractures, multiple trauma, oblique proximal fractures, distalthird fractures, and floating elbow. ${ }^{20,30-34}$ Decomas and Kaye assumed that obesity, cigarette smoking, metabolic bone disorder, cardiovascular disease, short oblique fractures, and open fractures were the most important risk factors in nonunion after nonoperative treatment. ${ }^{35}$ Moreover, in a review of nonoperative treatment for HSF, Ali et al found a higher rate of nonunion in proximal-third fractures. ${ }^{28}$

Two systematic reviews of randomized studies showed no advantage for operative or nonoperative methods for HSF treatments. ${ }^{8,11}$ Compression plating and intramedullary nailing are the two most common surgical fixation methods. Several studies have compared outcomes of these methods, but both were associated with some advantages and disadvantages. 9,14,36-38 Also, in a meta-analysis, Heineman et al found that the complication rate was lower with the ORIF method. ${ }^{9}$ There have been several studies demonstrating that plate fixation is the better surgical method for HSFs. ${ }^{19,36-40}$ Matsunaga et al compared the 1-year outcomes of 110 HSF patients treated by minimally invasive osteosynthesis with a bridge plate and functional bracing. According to their findings, mean DASH scores were significantly better in the surgical group after 6 months than patients that received functional bracing. In addition, the rate of nonunion ( 0 vs $15 \%$ ) and mean varusvalgus malunion $\left(2^{\circ}\right.$ and $10.5^{\circ}$, respectively) were found to be significantly lower in the surgical group. ${ }^{21}$ The latter results were close to our findings on general superiority of operative management.

Lastly, Harkin et al performed a retrospective cohort study in Australia on 126 HSF sufferers during a 7-year period. Among them, 30 participants primarily underwent surgery, while 96 were treated conservatively. The researchers found that approximately $54 \%$ of patients in the conservative group had timely union before 6.5 months, 13\% delayed union, and 33\% had not achieved union at all, whereas among those patients managed surgically, 63\% had timely union, 33\% delayed union, and only $4 \%$ did not achieve union. Harkin et al revealed a significant superiority favoring the operative group. However, no difference was present between plate and nail fixation regarding union or neurological injury. Furthermore, only $27 \%$ of nonunion patients in the conservative group who converted to surgical management achieved timely union. They concluded that early surgery had a significantly higher union rate than delayed surgery. Eventually, the authors concluded that the conservative management was associated with a higher rate of delayed union and nonunion than surgery. ${ }^{17}$ The latter finding was exactly in accordance with our results; however, we did not reach a statistically significant value, probably due to a smaller sample. Union in our RCT occurred about 1 month earlier in the operative group, which seems to be very important for those patients requiring a return to preinjury activities as soon as possible. Although the difference was not statistically significant, there were two patients $(6.6 \%)$ with nonunion in the nonoperative group, thereby requiring further operative treatment. As with any other study, there are some drawbacks in our study. Axial alignment was not evaluated and the cost of treatment was not compared between the groups. Further controlled trials with larger samples and longer follow-up are required to address these limitations. The authors assume that future high-quality RCTs could shed light on the issue and might find statistically significant differences.

\section{Conclusion}

Time to fracture union was significantly shorter in the surgical treatment group. Also, functional bracing for HSFs can be associated with a higher risk of nonunion. The authors recommend identifying high-risk patients for surgical treatment.

\section{Data-sharing statement}

The authors do not intend to share substantial data from this study. However, they are ready to share deidentified data in Excel format and all other study-related documents. These will be available for any period on demand from the editorial board via email to the corresponding authors.

\section{Acknowledgment}

This article has been extracted from the thesis written by Dr Hashem Abrishamkarzadeh at the School of Medicine, Shahid Beheshti University of Medical Sciences.

\section{Disclosure}

This RCT had no funding source and the authors report no conflicts of interest in this work. 


\section{References}

1. Court-Brown CM, Caesar B. Epidemiology of adult fractures: a review. Injury. 2006;37(8):691-697.

2. Malhan S, Thomas S, Srivastav S, et al. Minimally invasive plate osteosynthesis using a locking compression plate for diaphyseal humeral fractures. J Orthop Surg (Hong Kong). 2012;20(3):292-296.

3. Cole PA, Wijdicks CA. The operative treatment of diaphyseal humeral shaft fractures. Hand Clin. 2007;23(4):437-448.

4. Ekholm R, Adami J, Tidermark J, Hansson K, Törnkvist H, Ponzer S. Fractures of the shaft of the humerus. An epidemiological study of 401 fractures. J Bone Joint Surg Br. 2006;88(11):1469-1473.

5. Pogliacomi F, Devecchi A, Costantino C, Vaienti E. Functional longterm outcome of the shoulder after antegrade intramedullary nailing in humeral diaphyseal fractures. Chir Organi Mov. 2008;92(1):11-16.

6. Esmailiejah AA, Abbasian MR, Safdari F, Ashoori K. Treatment of humeral shaft fractures: minimally invasive plate osteosynthesis (MIPO) versus open reduction internal fixation. Trauma Mon. 2015;20(3):e26271.

7. Kapil Mani KC, Gopal Sagar DC, Rijal L, Govinda KC, Shrestha BL. Study on outcome of fracture shaft of the humerus treated nonoperatively with a functional brace. Eur J Orthop Surg Traumatol. 2013;23(3):323-328.

8. Gosler MW, Testroote M, Morrenhof JW, Janzing HM. Surgical versus non-surgical interventions for treating humeral shaft fractures in adults. Cochrane Database Syst Rev. 2012;1:CD008832.

9. Heineman DJ, Poolman RW, Nork SE, Ponsen K-J, Bhandari M. Plate fixation or intramedullary fixation of humeral shaft fractures. An updated meta-analysis. Acta Orthop. 2010;81(2):216-223. doi: $10.3109 / 17453671003635884$

10. Walker M, Palumbo B, Badman B, Brooks J, Van Gelderen J, Mighell M. Humeral shaft fractures: a review. J Shoulder Elbow Surg. 2011;20(5):833-844. doi:10.1016/j.jse.2010.11.030

11. Clement ND. Management of humeral shaft fractures; non-operative versus operative. Arch Trauma Res. 2015;4(2):e28013. doi:10.5812/ atr.28013v2.

12. Koch PP, Gross DF, Gerber C. The results of functional (Sarmiento) bracing of humeral shaft fractures. J Shoulder Elbow Surg. 2002;11 (2):143-150. doi:10.1067/mse.2002.121634

13. Matsunaga FT, Tamaoki MJ, Matsumoto MH, Dos Santos JB, Faloppa F, Belloti JC. Treatment of the humeral shaft fractures- -minimally invasive osteosynthesis with bridge plate versus conservative treatment with functional brace: study protocol for a randomised controlled trial. Trials. 2013;14:246. doi:10.1186/1745-6215-14-246

14. Denard A Jr, Richards JE, Obremskey WT, Tucker MC, Floyd M, Herzog GA. Outcome of nonoperative vs operative treatment of humeral shaft fractures: a retrospective study of 213 patients. Orthopedics. 2010;33:8.

15. Papasoulis E, Drosos GI, Ververidis AN, Verettas DA. Functional bracing of humeral shaft fractures. A review of clinical studies. Injury. 2010;41(7):e21-e27. doi:10.1016/j.injury.2009.05.004

16. Wallny T, Westermann K, Sagebiel C, Reimer M, Wagner UA. Functional treatment of humeral shaft fractures: indications and results. J Orthop Trauma. 1997;11:283-287. doi:10.1097/00005131199705000-00011

17. Harkin FE, Large RJ. Humeral shaft fractures: union outcomes in a large cohort. J Shoulder Elb Surg. 2017;26(11):1881-1888. doi:10.1016/j.jse.2017.07.001

18. Rosenberg N, Soudry M. Shoulder impairment following treatment of diaphysial fractures of humerus by functional brace. Arch Orthop Trauma Surg. 2006;126(7):437-440. doi:10.1007/s00402-006-0167-9

19. Bhandari M, Devereaux PJ, McKee MD, Schemitsch EH. Compression plating versus intramedullary nailing of humeral shaft fractures-a metaanalysis. Acta Orthop. 2006;77(2):279-284. doi:10.1080/1745367061 0046037
20. Jawa A, McCarty P, Doornberg J, Harris M, Ring D. Extra-articular distal-third diaphyseal fractures of the humerus. A comparison of functional bracing and plate fixation. $J$ Bone Joint Surg Am. 2006;88(11):2343-2347. doi:10.2106/JBJS.F.00334

21. Matsunaga FT, Tamaoki MJ, Matsumoto MH, Netto NA, Faloppa F, Belloti JC. Minimally invasive osteosynthesis with a bridge plate versus a functional brace for humeral shaft fractures: a randomized controlled trial. J Bone Joint Surg Am. 2017;99(7):583-592. doi:10.2106/JBJS.16.00628

22. Mahabier KC, Vogels LM, Punt BJ, Roukema GR, Patka P, Van Lieshout EM. Humeral shaft fractures: retrospective results of nonoperative and operative treatment of 186 patients. Injury. 2013;44 (4):427-430. doi:10.1016/j.injury.2012.08.003

23. Mast JW, Spiegel PG, Harvey JP Jr, Harrison C. Fractures of the humeral shaft: a retrospective study of 240 adult fractures. Clin Orthop Relat Res. 1975;112:254-262. doi:10.1097/00003086-197510 000-00033

24. Sarmiento A, Kinman PB, Galvin EG, Schmitt RH, Phillips JG. Functional bracing of fractures of the shaft of the humerus. $J$ Bone Joint Surg Am. 1977;59(5):596-601. doi:10.2106/00004623-197759050-00004

25. Pehlivan O. Functional treatment of the distal third humeral shaft fractures. Arch Orthop Trauma Surg. 2002;122(7):390-395. doi:10.10 07/s00402-002-0403-x

26. Oztürk I, Ertürer E, Uzun M, Akman S, Seçkin F. The effectiveness of functional bracing in the conservative treatment of humeral diaphyseal fractures. Acta Orthop Traumatol Turc. 2006;40(4):269-273.

27. Jensen AT, Rasmussen S. Being overweight and multiple fractures are indications for operative treatment of humeral shaft fractures. Injury. 1995;26(4):263-264. doi:10.1016/0020-1383(95)90012-M

28. Ali E, Griffiths D, Obi N, Tytherleigh-Strong G, Van Rensburg L. Nonoperative treatment of humeral shaft fractures revisited. J Shoulder Elbow Surg. 2015;24(2):210-214. doi:10.1016/j.jse.2014.05.009

29. Toivanen JA, Nieminen J, Laine HJ, Honkonen SE, Järvinen MJ. Functional treatment of closed humeral shaft fractures. Int Orthop. 2005;29:10-13. doi:10.1007/s00264-004-0612-8

30. Amillo S, Barrios RH, Martinez-Peric R, Losada JI. Surgical treatment of the radial nerve lesions associated with fractures of the humerus. J Orthop Trauma. 1993;7:211-215. doi:10.1097/000051 31-199306000-00002

31. Foster RJ, Swiontkowski MF, Bach AW, Sack JT. Radial nerve palsy caused by open humeral shaft fractures. J Hand Surg. 1993;18:121124. doi:10.1016/0363-5023(93)90255-2

32. Pollock FH, Drake D, Bovill EG, Day L, Trafton PG. Treatment of radial neuropathy associated with fractures of the humerus. J Bone Joint Surg Am. 1981;63:239-243. doi:10.2106/00004623-198163020-00009.

33. Ekholm R, Tidermark J, Törnkvist H, Adami J, Ponzer S. Outcome after closed functional treatment of humeral shaft fractures. $J$ Orthop Trauma. 2006;20:591-596. doi:10.1097/01.bot.0000246466. 01287.04

34. Rutgers M, Ring D. Treatment of diaphyseal fractures of the humerus using a functional brace. J Orthop Trauma. 2006;20:597-601. doi:10.1097/01.bot.0000249423.48074.82

35. Decomas A, Kaye J. Risk factors associated with failure of treatment of humeral diaphyseal fractures after functional bracing. $J$ La State Med Soc. 2010;162(1):33-35.

36. Gregory PR, Sanders RW. Compression plating versus intramedullary fixation of humeral shaft fractures. J Am Acad Orthop Surg. 1997;5 (4):215-223. doi:10.5435/00124635-199707000-00005

37. McCormack RG, Brien D, Buckley RE, McKee MD, Powell J, Schemitsch EH. Fixation of fractures of the shaft of the humerus by dynamic compression plate of intramedullary nail. A prospective, randomised trial. J Bone Joint Surg Br. 2000;82(3):336-339. doi:10.1302/0301-620X.82B3.0820336

38. Vennettilli M, Petrisor B, Athwal GS. Operative treatment of diaphyseal humeral fractures. J Hand Surg Am. 2011;36(5):905-906. doi:10.1016/j.jhsa.2011.01.032 
39. Bell MJ, Beauchamp CG, Kellam JK, McMurtry RY. The results of plating humeral shaft fractures in patients with multiple injuries. The Sunnybrook experience. J Bone Joint Surg Br. 1985;67(2):293-296. doi:10.1302/0301-620X.67B2.3980544
40. Niall DM, O'Mahony J, McElwain JP. Plating of humeral shaft fractures-has the pendulum swung back? Injury. 2004;35(6):580586. doi:10.1016/j.injury.2003.10.021

\section{Publish your work in this journal}

Orthopedic Research and Reviews is an international, peer-reviewed, open access journal that focusing on the patho-physiology of the musculoskeletal system, trauma, surgery and other corrective interventions to restore mobility and function. Advances in new technologies, materials, techniques and pharmacological agents are particularly welcome. The manuscript management system is completely online and includes a very quick and fair peer-review system, which is all easy to use. Visit http://www.dovepress.com/testimonials.php to read real quotes from published authors. 